\title{
The role of Diabetes Mellitus and BMI in the surgical treatment of ankle
}

\section{fractures.}

\section{Running title: DM and BMI In Ankle Fractures.}

Riccardo Maria Lanzetti*, Domenico Lupariello*, Teresa Venditto**, Matteo Guzzini*,

Antonio Ponzo*, Angelo De Carli*, Andrea Ferretti*.

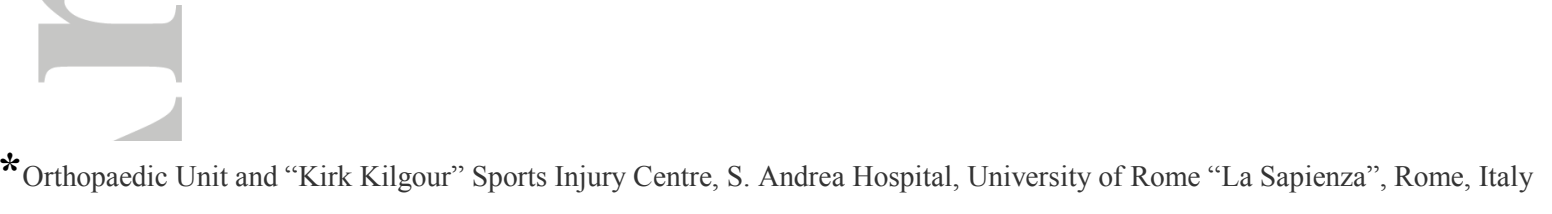

* Orthopaedic Unit and “Kirk Kilgour” Sports Injury Centre, S. Andrea Hospital, University of Rome "La Sapienza”, Rome, Italy

** Department of Physical Medicine and Rehabilita- tion. Board of Physical Medicine and Rehabilitation, Department of

Anatomy, Histology, Forensic Medicine and Orthopedics, "Sapienza” University of Rome, Italy

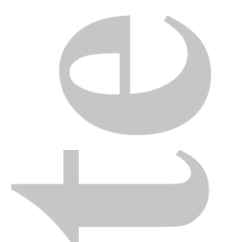

\section{Corresponding Author}

Domenico Lupariello, M.D.

Via grotta rossa 105300100 Rome Italy

Tel. 0633775006

Fax. 0633775580

Email: domenico.lupariello@gmail.com

\footnotetext{
This article has been accepted for publication and undergone full peer review but has not been through the copyediting, typesetting, pagination and proofreading process which may lead to differences between this version and the Version of Record. Please cite this article as doi: 10.1002/dmrr.2954
} 


\section{The role of Diabetes Mellitus and BMI in the surgical treatment of ankle}

\section{fractures.}

\section{ABSTRACT \\ Background}

Open reduction and internal fixation is the standard treatment for displaced ankle fractures. However, the presence of comorbidities such as diabetes mellitus and BMI is associated with poor bone quality, and these factors may predict the development of postoperative complications.

The study aim was to assess the role of diabetes mellitus and BMI in wound healing in patients younger than 65 years who were surgically treated for malleoli fractures.

\section{Methods}

Ninety patients, aged from 18 to 65 years old, with surgically treated ankle fracture, were retrospectively enrolled. Patients were classified in two groups: patient with diabetes and patients without diabetes (insulin-dependent and non-insulin dependent). All patients were assessed for wound complications, VAS and Foot and Ankle Disability Index (FADI) were assessed for all patients. Logistic regression was used to identify the risk of wound complications after surgery using the following factors as explanatory variables: age, gender, duration of surgery, BMI, hypercholesterolemia, smoking habit, diabetes mellitus and high blood pressure.

\section{Results}

In total, $38.9 \%$ of patients showed wound complications. Of them, $17.1 \%$ were non-diabetics and $82.9 \%$ were diabetics. We observed a significant association between DM and wound complications after surgery $(\mathrm{p}=0.0051)$. 
Logistic regression analysis revealed that DM $(p<0.001)$ and BMI $(p=0.03)$ were associated with wound complications. The odds of having a postoperative wound complication were increased 0.16 times in the presence of diabetes and 1.14 times for increasing BMI.

\section{Conclusion}

This study showed that Diabetes Mellitus and higher BMI delay the wound healing and increase the complication rate in young adult patients with surgically treated bimalleolar fractures.

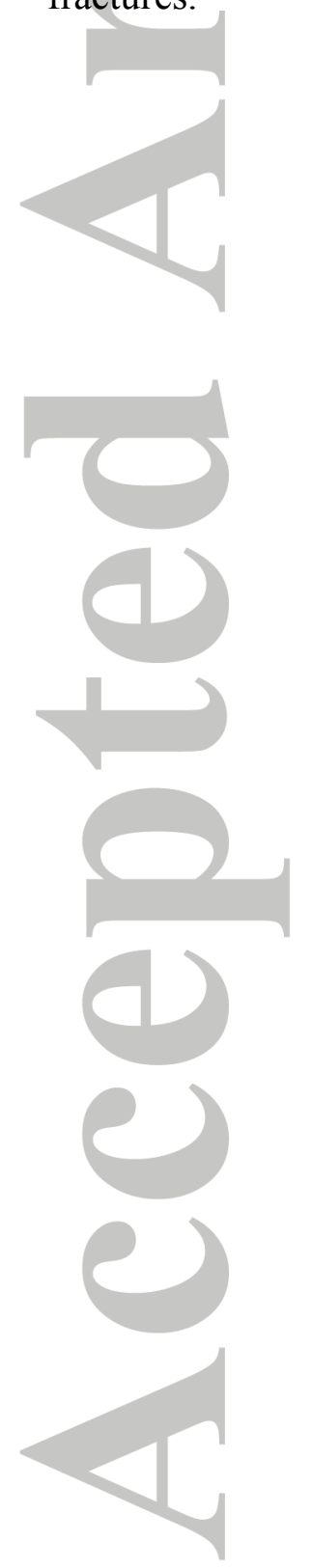




\section{INTRODUCTION}

Ankle fractures (AF) represent $10 \%$ of all fractures, with an incidence of 184 per 100.000 person-years in northern Europe ${ }^{1-3}$, making these the second most common lower limb fractures after hip fractures ${ }^{4}$. Young active men with high-energy trauma and older women with low-energy trauma are the two most commonly affected groups ${ }^{5}$.

Complications associated with both nonoperative and operative management are an important consideration in the treatment decision. For stable nondisplaced fractures, nonoperative treatment is the most appropriate management, as operative management of these types of injuries could expose patients to surgery-associated risks ${ }^{6}$. Open reduction and internal fixation represent the standard treatment for displaced ankle fractures, despite the overall rate of complications after surgery, which varies from $5 \%$ to $40 \%{ }^{5,7}$. Moreover, the presence of comorbidities such as diabetes mellitus and peripheral vascular diseases, associated with poor bone quality, may be predictive factors for the development of complications following operative management of ankle fractures ${ }^{8-10}$. In particular, diabetes is an increasingly prevalent disease with significant associated morbidity and mortality ${ }^{11,12}$. Patients with DM have a unique set of characteristics including impaired wound healing; fracture healing; immune function; peripheral neuropathy and peripheral arterial disease, making management of these fractures especially difficult. For these reasons, ankle fractures in young adult patients with diabetes remain challenging due to the high complication ${ }^{13-15}$.

The literature is not conclusive regarding the risk of postoperative complications after the operative management of ankle fractures in young adult patients with diabetes. Therefore, the aim of the present study was to characterize the role of diabetes mellitus in wound healing in patients younger than 65 years who were surgically treated for malleoli fractures.

The hypothesis was that the presence of Diabetes Mellitus negatively influences wound healing in patients younger than 65 years surgically treated for ankle fractures. 


\section{MATERIALS AND METHODS}

We performed a retrospective case control study. The study population included all consecutive patients aged between 18 and 65 years with ankle fractures that were treated by a single surgeon between March 2012 and December 2014.

The study protocol was approved by the hospital's Ethical Review Board and was conducted in accordance with the principles of the Declaration of Helsinki and its amendments. We fully informed all the subjects about the characteristics of the study and they gave their consent.

The exclusion criteria were the following: previous fracture of the ankle, previous local and general infective disease, age $<18$ years and $>65$ years, previous surgery on the index ankle and non-operatively treated fracture.

Patients were classified in two groups: non-diabetics and diabetics (insulin-dependent and noninsulin dependent). A standardized questionnaire was used to obtain information about diabetes mellitus (presence or absence), smoking habit (presence or absence), body mass index (BMI), and hypercholesterolemia. BMI was calculated as weight $(\mathrm{kg})$ divided by height squared $\left(\mathrm{m}^{2}\right)$. Medical data also included the duration of surgery, gender, high blood pressure and wound complications.

Categorization of wound complications was based on the treatment required to achieve resolution. The complication-free category represented normal wound-healing and suture or staple removal without additional measures. The omplications category included wound infection (superficial infection and/or minor wound dehiscence), delayed wound healing, deep vein thrombosis, pulmonary embolism, and patients who required a return to the operating room for additional surgical treatment of wound complications. These interventions included any form of surgical irrigation and debridement, with or without removal of hardware. According to Konarth et al. ${ }^{16}$, patients were treated within $<5$ days. 


\section{Clinical evaluation}

The Visual Analogue Scale (VAS) and Foot and Ankle Disability Index (FADI) were used as outcome measures to evaluate the level of pain and ankle function, respectively, at baseline. The VAS consists of a 10-cm horizontal line (with $0 \mathrm{~cm}$ referring to "no pain" and $10 \mathrm{~cm}$ to the "the worst pain ever") on which patients were invited to draw a line indicating pain intensity. The distance is measured and pain is recorded on a 10 -point scale ${ }^{17}$.

The FADI has 26 items. Each item is scored from 0 (unable to do) to 4 (no difficulty at all). The 4 pain items of the FADI are scored 0 (none) to 4 (unbearable). The FADI has a total point value of 104 points. The FADI is scored separately as percentages, with $100 \%$ representing no dysfunction $^{18}$.

\section{Post-operative protocol.}

For the first 4 weeks, patients were immobilized with a cast, with the recommendation to elevate the ankle above the heart and not to bear weight on the affected leg. Patients were advised to begin passive and active range of motion.

From 4 to 8 weeks, patients were advised to gradually progress to full weight bearing, restoration of normal gait mechanics, full active and passive range of motion, isometric and early isotonic ankle exercises and proprioception training.

From 8 to 12 weeks, patients reached the restoration of full range of motion in all planes; they started advanced ankle and intrinsic foot strengthening, pool running progressing to dry land and linear progression to lateral and rotational functional movements.

In patients who underwent syndesmosis repair, weight bearing was allowed after trans syndesmotic screw removal.

\section{Statistical Analysis}

Following verification by use of the Kolmogorov-Smirnov test that the variables were normally distributed, we employed parametric tests for statistical data analysis. All wound complications 
(major and minor) were treated as the dependent variable. To evaluate the risk of wound complications in non-diabetics and diabetics subjects, odds ratios (ORs) were calculated according to Altman. An OR of $>1.0$ meant that DM was associated with a statistically significantly higher risk of wound complications.

Logistic regression was used to identify the risk of wound complications after surgery using the following factors as explanatory variables: age, gender, duration of surgery, BMI, hypercholesterolemia, smoking habits, diabetes mellitus, and high blood pressure. All statistical tests were 2 -sided with a probability level of 0.05 , and all results are expressed with the corresponding 95\% confidence interval. SPSS version 18 was used for calculations.

\section{RESULTS}

From the original 122 patients, 32 patients were lost to follow up or did not meet the inclusion criteria and 90 were available for the study. Sample characteristics are shown in

Table 1 and Table 2. According to the sample, 38.9\% (N=35) showed wound complications (6 wound infection requiring revision surgery, 12 wound infections treated with antibiotics, 7 cases of delayed wound healing, 6 cases of deep vein thrombosis, 4 cases of pulmonary embolism), no cases of amputation or fixation failure were seen. Of all patients with complication, $17.1 \%(\mathrm{~N}=6)$ were non-diabetics and $82.9 \%(\mathrm{~N}=29)$ were diabetics. We observed a significant association between DM and wound complications after AF surgery $(\mathrm{OR}=4.33$, CI: $1.55-12.09 ; \mathrm{p}=0.0051)$. All fractures healed within 5 months, with no differences between the two groups. Logistic regression analysis revealed that $\mathrm{DM}(\mathrm{p}<0.001)$ and $\operatorname{BMI}(p=0.03)$ were associated with the occurrence of wound complications. No differences were seen in patients with or without insulin-dependent diabetes. The odds of having a postoperative wound complication were increased 0.16 times in the presence of diabetes. The odds of experiencing a wound complication with incrementally increasing 
patient BMI was 1.14 (95\% confidence interval, 1.01 to 1.29$)$. The results of regression analysis are shown in Table 3.

\section{DISCUSSION}

Infection rates for patients with diabetes undergoing surgery for ankle fractures can be as high as $60 \%$ and failure to treat infection can lead to amputation in $42 \%$ and mortality in $11 \%$ of $\operatorname{cases}^{18}$. The most important finding of our study is that Diabetes Mellitus is an independent risk factor for wound complications in patients younger than 65 years surgically treated for bimalleolar fractures.

Flynn et al. studied 98 patients (73 non-diabetics and 25 diabetics) ranging in age from 18 to 85 years, who were treated for closed ankle fractures by either surgical or non-surgical methods. Agreeing with our findings, the authors reported that the risk of infection in the diabetic population $(32 \%)$ was four times that in the non-diabetic population $(8 \%)^{15}$, even if they included patients older than 65 years and those who were treated conservatively.

Given the high rates of infection and amputation, perioperative glycemic control is very important in DM patients. Indeed, prolonged hyperglycemia inhibits enzymatic glycosylation, producing irreversible advanced glycation end products (AGEs), which lead to disruption of soft tissues and impaired function ${ }^{19}$. Abnormal glucose metabolism results in vasculopathy, neuropathy, and inhibition of wound healing and impaired immune function thus creating conditions that predispose to infection ${ }^{20}$. Moreover, neuroarthropathy has been shown as a significant risk factor for developing a wide range of complications. Possible delayed complications include loss of reduction, metalwork failure, nonunion, arthrosis and Charcot arthropathy ${ }^{5}$.

In our study, age, gender, duration of surgery, hypercholesterolemia, smoking habits, high blood pressure and FADI and VAS scores were not significantly associated with the occurrence 
of complications. Zaghloul et al. ${ }^{10}$ found, in a cohort of 186 patients aged older than 65 years, that smoking, age, gender and diabetes were significantly associated with the occurrence of complications, whereas coronary artery disease and fracture type did not have a significant effect on the outcome.

Moreover, in a younger population of patients surgically treated for ankle fracture, the risk factors for complications significantly differed from those previously described for elderly patients $^{21}$

Many authors have already described the potential risk factors for complications and revision surgery in the geriatric population, but the data on young adults lack definitive evidences ${ }^{22,23}$. However, comparing our results with those of other series on elderly patients could be confounding, because the complication rate in geriatric cohorts is higher. In fact, Anderson et al. ${ }^{24}$ reported a complication rate of $40 \%$ in their series of 25 patients. They noted that their complication rate was significantly higher than that in their younger cohort (11\%).

Moreover, data from the previous studies disagree on the factors that increase the risk of ankle fracture.

In a recent study of 237 patients Aigner et al. ${ }^{25}$ analyzed age, timing of operative treatment, fracture type, ASA score, operating time, body mass index, Charlson score, diabetes mellitus, chronic obstructive pulmonary disease, peripheral vascular disease, osteoporosis, coronary artery disease, use of a tourniquet, tourniquet time and surgeon's experience. They found that operative time was the only modifiable factor in the development of complications and revision surgery. Age, Diabetes and other comorbidities were not associated with complications.

Another important finding of our study is that BMI influences wound healing. This is in line with findings reported in the literature. Indeed, obesity has been linked to increased incidences of infectious diseases, including periodontal infections, influenza, bacterial pneumonia, nosocomial and surgical site infection ${ }^{26}$. Furthermore, obesity has been shown to impair 
immunological responses in adults ${ }^{27}$. Altered metabolism of the obese has been shown both in the steady state and during infection. Hormone resistance, inflammation and alterations in nutrient levels all influence T-cell activation, function and survival. The peripheral vascular supply is also compromised in obese patients, delaying physiological wound healing.

The data from our study suggest that a minimal invasive or percutaneous surgery, when indicated, is likely preferable in a higher-risk group of patients with Diabetes Mellitus and higher BMI. However, further studies are needed to assess if a minimally invasive or percutaneous surgery could improve wound healing in patients with diabetes Mellitus and ankle fractures.

The results of the present study are limited by several factors. We did not consider the timing of surgery as an explanatory variable. We did not provide long-term follow-up data. However, the goal of the present study was to report early complications and not long-term outcomes.

The most important limitation of this study is the lack of evaluation of peripheral neuropathy, which could interfere with the final conclusions.

A strength of the present study is the high number of patients, and the high number of comorbidities analyzed. A multivariate analysis was performed to identify independent risk factors for the development of complications. This study showed that Diabetes Mellitus and higher BMI delay wound healing and increase the complication rate in young adult patients with surgically treated bimalleolar fractures.

\section{Conflict of interest}

The authors declare no conflict of interest.

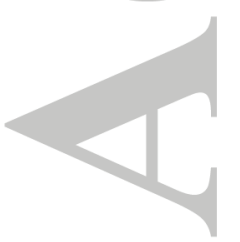




\section{REFERENCES}

1. Salai M, Dudkiewicz I, Novikov I, Amit Y, Chechick A. The epidemic of ankle fractures in the elderly-is surgical treatment warranted? Archives of orthopaedic and trauma surgery. 2000;120(9):511-3.

2. Court-Brown CM, McBirnie J, Wilson G. Adult ankle fractures — an increasing problem? Acta orthopaedica Scandinavica. 1998;69(1):43-7.

3. Donken CC, Al-Khateeb H, Verhofstad MH, van Laarhoven CJ. Surgical versus conservative interventions for treating ankle fractures in adults. Cochrane Database Syst Rev. 2012 Aug 15;(8):CD008470.

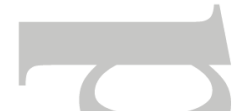

4. Court-Brown CM, Caesar B. Epidemiology of adult fractures: a review. Injury. 2006;37(8):691-7.

5. Mehta SS, Rees K, Cutler L, Mangwani J. Understanding risks and complications in the management of ankle fractures. Indian journal of orthopaedics. 2014;48(5):445.

6. Herscovici D, Scaduto J, Infante A. Conservative treatment of isolated fractures of the medial malleolus. Bone \& Joint Journal. 2007;89(1):89-93.

7. Leyes M, Torres R, Guillén P. Complications of open reduction and internal fixation of ankle fractures. Foot and ankle clinics. 2003;8(1):131-47. 
8. Costigan W, Thordarson DB, Debnath UK. Operative management of ankle fractures in patients with diabetes mellitus. Foot \& ankle international. 2007;28(1):32-7.

9. Ovaska MT, Mäkinen TJ, Madanat R, Huotari K, Vahlberg T, Hirvensalo E, et al. Risk factors for deep surgical site infection following operative treatment of ankle fractures. J Bone Joint Surg Am. 2013;95(4):348-53.

10. Zaghloul A, Haddad B, Barksfield R, Davis B. Early complications of surgery in operative treatment of ankle fractures in those over 60: a review of 186 cases. Injury. 2014;45(4):780-3.

11. Engelgau MM, Geiss LS, Saaddine JB, Boyle JP, Benjamin SM, Gregg EW, et al. The evolving diabetes burden in the United States. Annals of internal medicine. 2004;140(11):945-50.

12. Rawlings AM, Sharrett AR, Schneider AL, Coresh J, Albert M, Couper D, et al. Diabetes in Midlife and Cognitive Change Over 20 YearsA Cohort StudyDiabetes in Midlife and Cognitive Change Over 20 Years. Annals of internal medicine. 2014;161(11):785-93.

13. Basques BA, Miller CP, Golinvaux NS, Bohl DD, Grauer JN. Morbidity and readmission after open reduction and internal fixation of ankle fractures are associated with preoperative patient characteristics. Clinical Orthopaedics and Related Research ${ }^{\circledR}$. 2015;473(3):1133-9. 
14. Bibbo C, Lin SS, Beam HA, Behrens FF. Complications of ankle fractures in diabetic patients. Orthopedic Clinics of North America. 2001;32(1):113-33.

15. Flynn JM, Rio FR-d, Pizá PA. Closed ankle fractures in the diabetic patient. Foot \& ankle international. 2000;21(4):311-9.

16. Konrath G, Karges D, Watson JT, Moed BR, Cramer K. Early versus delayed treatment of severe ankle fractures: a comparison of results. Journal of orthopaedic trauma. $1995 ; 9(5): 377-80$.

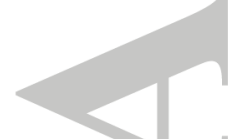

17. Hawker GA, Mian S, Kendzerska T, French M. Measures of adult pain: Visual analog scale for pain (vas pain), numeric rating scale for pain (nrs pain), mcgill pain questionnaire (mpq), short-form mcgill pain questionnaire (sf-mpq), chronic pain grade scale (cpgs), short form-36 bodily pain scale (sf-36 bps), and measure of intermittent and constant osteoarthritis pain (icoap). Arthritis care \& research. 2011;63(S11):S240-S52.

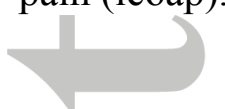

18. Hale SA, Hertel J. Reliability and sensitivity of the Foot and Ankle Disability Index in subjects with chronic ankle instability. Journal of Athletic training. 2005;40(1):35.

19. Brownlee M, Cerami A, Vlassara H. Advanced glycosylation end products in tissue and the biochemical basis of diabetic complications. New England Journal of Medicine. $1988 ; 318(20): 1315-21$.

20. Jones KB, Maiers-Yelden K, Marsh J, Zimmerman M, Estin M, Saltzman C. Ankle fractures in patients with diabetes mellitus. Bone \& Joint Journal. 2005;87(4):489-95. 
21. SooHoo NF, Krenek L, Eagan MJ, Gurbani B, Ko CY, Zingmond DS. Complication rates following open reduction and internal fixation of ankle fractures. $\mathrm{J}$ Bone Joint Surg Am. 2009 May;91(5):1042-9.

22. Ahmed Zaghloul, Behrooz Haddad, Richard Barksfield, Ben Davis. Early complications of surgery in operative treatment of ankle fractures in those over 60: A review of 186 cases. Injury, Int. J. Care Injured 45 (2014) 780-783.

23. Michael J. Lynde, Travis Sautter, Graham A. Hamilton, John M. Schuberth.

Complications after open reduction and internal fixation of ankle fractures in the elderly. Foot and Ankle Surgery 18 (2012) 103-107.

24 Anderson SA, Li X,_Franklin P, Wixted_JJ. Ankle fractures in the elderly: initial and long-term outcomes. Foot Ankle Int 2008;29:1184-8.

25. Aigner R, Salomia C, lechler P, Pahl R, Frink M. Relationship of prolonged operative time and comorbidities with complications after geriatric ankle fractures. Foot Ankle int 2017 Jan, 38 (1): 41-48.

26. Huttunen R, Syrjänen J. Obesity and the risk and outcome of infection. International Journal of Obesity. 2013;37(3):333-40.

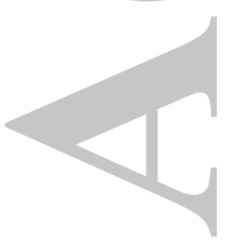


27. Park H-L, Shim S-H, Lee E-Y, Cho W, Park S, Jeon H-J, et al. Obesity-induced chronic inflammation is associated with the reduced efficacy of influenza vaccine. Human vaccines \& immunotherapeutics. 2014;10(5):1181-6.

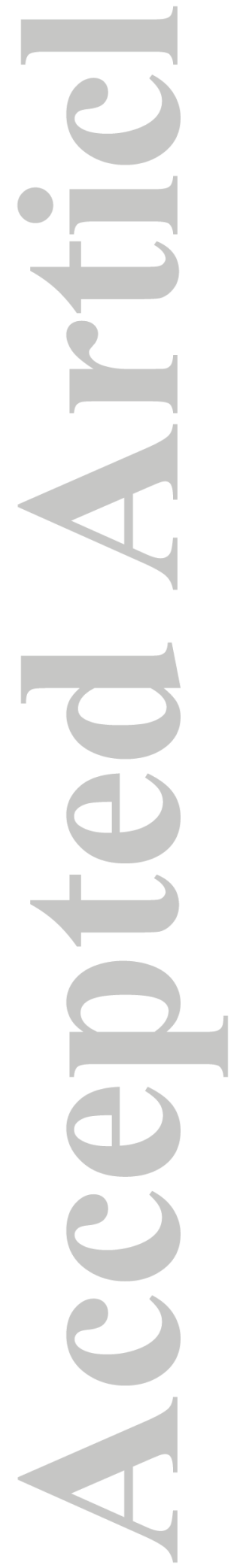


Table 1:Patient's baseline features.

\begin{tabular}{|c|c|}
\hline Age (SD) & $49.7 \pm 12.22$ \\
\hline Gender (Female/Male) & $52 / 38$ \\
\hline BMI $\left(\mathrm{kg} / \mathrm{m}^{2}\right)$ & $27.27 \pm 4.68$ \\
\hline Diabetes Mellitus & $32 / 58$ \\
\hline Smoking Habit (Yes/No) & $35 / 55$ \\
\hline Hypercholesterolemia & $36 / 54$ \\
\hline Arterial Hypertension & $37 / 53$ \\
\hline FADI & $78.74 \pm 17.38$ \\
\hline VAS & $7.21 \pm 3.04$ \\
\hline $\begin{array}{ll}\text { Complication, } \mathbf{n}(\mathbf{\%}) \\
\checkmark & \text { Wound infection requiring } \\
& \text { revision surgery } \\
\checkmark & \text { Wound infection treated } \\
& \text { with antibiotics } \\
\checkmark & \text { Delayed wound healing } \\
\checkmark & \text { Deep vein thrombosis } \\
\checkmark & \text { Pulmonary embolism }\end{array}$ & $\begin{array}{c}6(17.14 \%) \\
12(34.28 \%) \\
7(20 \%) \\
6(17.14 \%) \\
4(11.44 \%)\end{array}$ \\
\hline
\end{tabular}

BMI: body mass index; VAS: Visual Analogue Scale;

FADI: Foot and Ankle Disability Index 
Table 2: Features of the groups.

\begin{tabular}{|l|l|l|}
\hline \multicolumn{2}{|l|}{ Diabetic patients } & Non diabetic patients \\
\hline Fracture types & $\begin{array}{l}\text { 15 bimalleolar, 10 lateral } \\
\text { malleolus, 7 medial malleolus }\end{array}$ & $\begin{array}{l}\text { 32 bimalleolar, 16 lateral } \\
\text { malleolus, 10 medial } \\
\text { malleolus }\end{array}$ \\
\hline BMI & $28.75 \pm 3.1$ & $26.63 \pm 4.2$ \\
\hline VAS & $6.44 \pm 2.8$ & $7.01 \pm 3.25$ \\
\hline FADI & $80.65 \pm 16.7$ & $77.81 \pm 18.56$ \\
\hline
\end{tabular}


Table 3: Multiple regression analysis model

\begin{tabular}{|l|c|c|c|c|c|}
\hline \multicolumn{1}{|c|}{ Risk Factors } & B & Exp(B) & \multicolumn{2}{c|}{$\begin{array}{c}\text { E5\%(B) Confidence Interval for } \\
\text { Lxp (B) Bound Upper Bound }\end{array}$} & P value \\
\hline Constant & & & & 1.09 & 0.23 \\
\hline Age & -7.08 & & 0.98 & 9.73 & 0.13 \\
\hline Gender & 0.03 & 1.03 & 0.75 & 1.29 & $\mathbf{0 . 0 3}$ \\
\hline BMI & 1 & 2.71 & 1.01 & 0.53 & $<\mathbf{0 . 0 0 1}$ \\
\hline Diabetes Mellitus & -1.85 & 0.16 & 0.05 & 3.22 & 0.84 \\
\hline Smoking Habit & -0.14 & 0.87 & 0.24 & 4.51 & 0.60 \\
\hline Hypercholesterolemia & 0.32 & 1.38 & 0.42 & 6.14 & 0.47 \\
\hline Arterial Hypertension & 0.49 & 1.63 & 0.43 & 1.02 & 0.29 \\
\hline FADI & -0.02 & 0.98 & 0.95 & 1.34 & 0.39 \\
\hline VAS & 0.09 & 1.09 & 0.89 & 1.06 & 0.11 \\
\hline Time of surgery & 0.02 & 1.02 & 1 & & $\mathbf{0 . 0 3}$ \\
\hline
\end{tabular}

